Article

\title{
Genistein Supplementation and Cardiac Function in Postmenopausal Women with Metabolic Syndrome: Results from a Pilot Strain-Echo Study
}

\author{
Cesare de Gregorio ${ }^{1}$, Herbert Marini ${ }^{1}$, Angela Alibrandi ${ }^{2}$, Antonino Di Benedetto ${ }^{1}$, \\ Alessandra Bitto ${ }^{1}$, Elena Bianca Adamo ${ }^{3}$, Domenica Altavilla ${ }^{4}$, Concetta Irace ${ }^{5}$, \\ Giacoma Di Vieste ${ }^{1}$, Diego Pancaldo ${ }^{6}$, Roberta Granese ${ }^{4}$, Marco Atteritano ${ }^{1}$, \\ Salvatore Corrao ${ }^{7,8}$, Giuseppe Licata ${ }^{7}$, Francesco Squadrito ${ }^{1}$ and Vincenzo Arcoraci ${ }^{1, *}$ \\ 1 Department of Clinical and Experimental Medicine, University of Messina, 98100 Messina, Italy; \\ cdegregorio@unime.it (C.d.G.); hrmarini@unime.it (H.M.); adibenedetto@unime.it (A.D.B.); \\ abitto@unime.it (A.B.); jackydv@hotmail.it (G.D.V.); matteritano@unime.it (M.A.); fsquadrito@unime.it (F.S.) \\ Department of Economics, Business, Environmental Science and Quantitative Methodologies, \\ University of Messina, 98100 Messina, Italy; aalibrandi@unime.it \\ 3 Department of Experimental, Specialized Medical and Surgical and Odonto-stomatological Sciences, \\ University of Messina, 98100 Messina, Italy; elenabianca.adamo@unime.it \\ 4 Department of Pediatric, Gynecological, Microbiological, and Biomedical Sciences, University of Messina, \\ 98100 Messina, Italy; daltavilla@unime.it (D.A.); roberta.granese@unime.it (R.G.) \\ 5 Department of Clinical and Experimental Medicine, University Magna Græcia, 88100 Catanzaro, Italy; \\ irace@unicz.it \\ 6 Department of Cardiology, SS. Annunziata Hospital, 12038 Savigliano (CN), Italy; pancaldodiego@libero.it \\ 7 Centre of Research for Effectiveness and Appropriateness in Medicine (C.R.E.A.M.), Di.Bi.M.I.S., \\ University of Palermo, 90127 Palermo, Italy; s.corrao@tiscali.it (S.C.); licatag@unipa.it (G.L.) \\ 8 Department of Internal Medicine, National Relevance and High Specialization Hospital Trust ARNAS \\ Civico, Di Cristina, Benfratelli, 90127 Palermo, Italy \\ * Correspondence: Vincenzo.Arcoraci@unime.it; Tel.: +39-90-221-3994
}

Received: 21 April 2017; Accepted: 31 May 2017; Published: 7 June 2017

\begin{abstract}
Genistein, a soy-derived isoflavone, may improve cardiovascular risk profile in postmenopausal women with metabolic syndrome (MetS), but few literature data on its cardiac effects in humans are available. The aim of this sub-study of a randomized double-blind case-control study was to analyze the effect on cardiac function of one-year genistein dietary supplementation in 22 post-menopausal patients with MetS. Participants received $54 \mathrm{mg} /$ day of genistein $(n=11)$ or placebo $(n=11)$ in combination with a Mediterranean-style diet and regular exercise. Left ventricular (LV) systolic function was assessed as the primary endpoint, according to conventional and strain-echocardiography measurements. Also, left atrial (LA) morphofunctional indices were investigated at baseline and at the final visit. Results were expressed as median with interquartile range (IQ). A significant improvement of LV ejection fraction (20.3 (IQ 12.5) vs. -1.67 (IQ 24.8); $p=0.040)$ ), and LA area fractional change (11.1 (IQ 22.6) vs. $2.8(9.5) ; p=0.034)$ ) were observed in genistein patients compared to the controls, following 12 months of treatment. In addition, body surface area indexed LA systolic volume and peak LA longitudinal strain significantly changed from basal to the end of the study in genistein-treated patients. One-year supplementation with $54 \mathrm{mg} /$ day of pure genistein improved both LV ejection fraction and LA remodeling and function in postmenopausal women with MetS.
\end{abstract}

Keywords: genistein; metabolic syndrome; menopause; cardiac function; echocardiography 


\section{Introduction}

Estrogen favorably influences calcium homeostasis, serum lipid levels, blood pressure control, inflammatory status, and vascular reactivity in women [1-5]. Data from Italian and other European registries indicate that postmenopausal women presenting with traits of metabolic syndrome (MetS), mostly diabetes mellitus (DM) and hyperlipemia, are at high risk of cardiovascular (CV) events $[1,6,7]$. Moreover, the use of lipid-lowering therapy is strongly influenced by reimbursement criteria revision, and the female gender was identified as a patient-related predictor of low adherence [8-10]. The advantages of estrogen supplementation are preserved in early menopause, failing to maintain cardiovascular protection, thus further therapeutic options continue to be studied [11-13]. Genistein aglycone (hereinafter referred to as genistein) is a soy isoflavone, which has progressively gained clinical consideration for the management of postmenopausal symptoms. Its molecular structure resembles that of $17 \beta$-estradiol and binds the same estrogen-receptors in a dose-dependent manner. Regular supplementation in combination with a Mediterranean-style diet, regular exercise, and medical therapy improve CV risk, endothelial function, and vascular reactivity in MetS women, although, to date, very little data are available concerning the effect of genistein on heart function [12,14-18].

The aim of this study was therefore to investigate whether genistein therapy might influence heart function in postmenopausal patients with MetS.

\section{Materials and Methods}

\subsection{Design and Setting}

A group of postmenopausal women, affected by type-2 DM and free from previous CV events, was enrolled from the population of postmenopausal women referred to the Department of Clinical and Experimental Medicine (University Hospital, Messina, Italy) for MetS. All patients were of Caucasian origin. This study was planned as a sub-study aimed to investigate the influence of genistein on heart function, from the original randomized multicenter clinical trial (clinicaltrials.gov registration NCT00541710) managed in collaboration with the University of Palermo (Palermo, Italy) and the University of Magna Graecia (Catanzaro, Italy) [16]. All patients gave written informed consent and the Ethical Committee of the University Hospital of Palermo approved the protocol of this study (approval number: RODA-12254).

Diagnosis of MetS was made considering the presence of at least three criteria among those provided by the modified US National Cholesterol Education Program Adult Treatment Panel III [19], as follows: (a) waist circumference $>88 \mathrm{~cm}$; (b) triglycerides $>8.3 \mathrm{mmol} / \mathrm{L}$ or on drug treatment for elevated triglycerides; (c) high-density lipoprotein cholesterol (HDL-C) $<2.8 \mathrm{mmol} / \mathrm{L}$ or on drug treatment for reduced HDL-C; (d) type-2 DM, according to current guidelines [20]; (e) blood pressure $>130 / 90 \mathrm{~mm} \mathrm{Hg}$ or on anti-hypertensive therapy. Criteria for menopause included: absence of menstrual period in the preceding year, follicle-stimulating hormone level $>50 \mathrm{IU} / \mathrm{L}$, and $17 \beta$-estradiol serum level $\leq 100 \mathrm{pmol} / \mathrm{L}(\leq 27 \mathrm{pg} / \mathrm{mL})[2,3]$.

Family history, physical examination, measurement of body surface area (BSA, $\mathrm{m}^{2}$ ), waist circumference $(\mathrm{cm})$ and body mass index $\left(\mathrm{BMI}, \mathrm{kg} / \mathrm{m}^{2}\right.$ ), routine laboratory sampling (fasting glucose, total cholesterol, HDL-C, low-density lipoprotein cholesterol (LDL-C), triglyceride levels), fasting serum insulin, and the insulin resistance index by the homeostasis model assessment for insulin resistance (HOMA-IR) were carried out at baseline, 6 months, and 12 months of therapy. Visfatin, adiponectin, and homocysteine (HCY) serum levels were also evaluated, as previously described [16].

Patients with a previous or current cardiovascular event, renal or hepatic failure, coagulopathy, cancer, use of sex hormones or estrogen receptor modulators, steroids, long term treatment with non-steroidal anti-inflammatory drugs, alcohol abuse, or those who smoked more than two cigarettes per day were excluded from the study. 
Hypoglycaemic and/or anti-hypertensive drugs were continued during the study period, if required. Fasting glucose target $<8.3 \mathrm{mmol} / \mathrm{L}$ and blood pressure $\leq 135 / 85 \mathrm{~mm} \mathrm{Hg}$ were recommended to be achieved in all study participants.

Left ventricular (left ventricle, LV) systolic function was evaluated as the primary endpoint to analyze the effect of genistein on cardiac function. In particular, LV systolic function and left atrial (left atrium, LA) morphofunctional indices were investigated according to high-resolution strain-echocardiography imaging measurements.

\subsection{Randomization}

Patients from the original trial were assigned by using a computer-generated double-blind randomization sequence to receive genistein (genistein group) or placebo (control group) twice a day. Both tablets were supplied by Mastelli srl (Sanremo, Italy). The genistein daily dose was $54 \mathrm{mg}$ and tablets were identical to the placebo in appearance and taste. Genistein serum levels were measured both at baseline and the final visit, as previously described [16,21]. Only the first 11 patients of each group underwent ultrasound studies, due to a budget reduction from the original proposal (Figure 1). Patients were enrolled according to the computer-generated double-blind randomization sequence, using the first randomization numbers for each group and maintaining the blinding of researchers directly involved in the study. Genistein and placebo were given for 12 months.

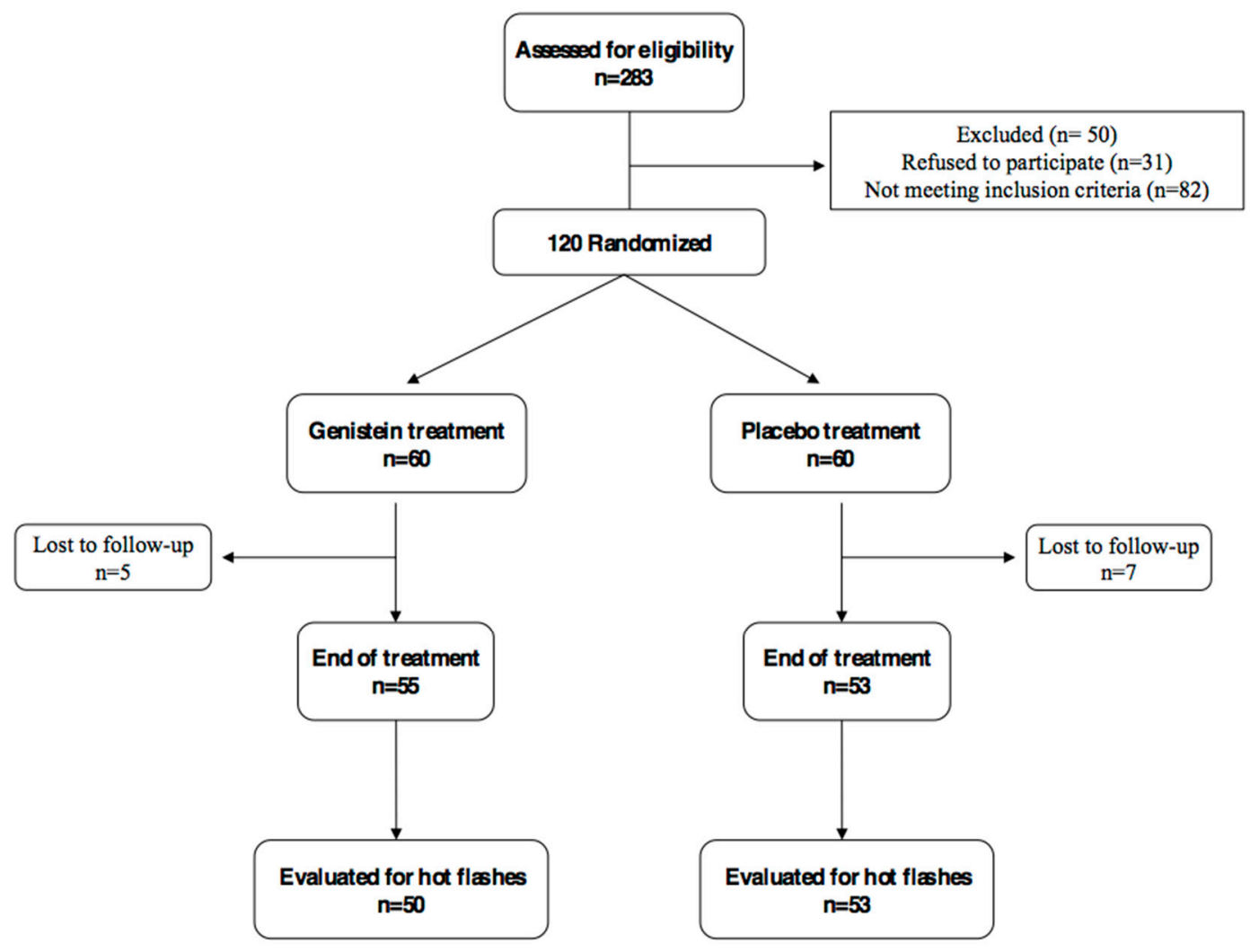

Figure 1. CONSORT diagram (Consolidated Standards of Reporting Trials diagram). The first 11 patients of each arm underwent ultrasound study.

Sample size was calculated in the parent study to provide $80 \%$ power to detect an expected absolute between-group difference in HOMA-IR of $20 \%$ after one year of treatment, assuming a two-tailed level of 0.05 as significant [16]. 


\subsection{Diet and Exercise}

Patients were all recommended to follow a Mediterranean-style dietary regimen (25-30\% fat, less than $10 \%$ saturated fatty acids, $55-60 \%$ carbohydrates, and $15 \%$ protein), but further intake of soy products or supplements was discouraged.

Regular exercise, such as walking or biking for 80 to 100 min per week, was also suggested to participants and was recorded weekly for each patient. Dietary and treatment adherence was recorded at each visit.

\subsection{Electrocardiogram and Echocardiogram}

After performing a conventional 12-lead electrocardiogram (ECG), ultrasound study was carried out with a commercially available station (Esaote Mylab 30, Florence, Italy), equipped with an M-mode, two-dimensional color-Doppler and strain-feature analysis. Imaging was achieved by the conventional five trans-thoracic views (parasternal long-axis and short-axis, apical 2, 4, and 5 chambers). Quantitative findings were measured as the mean value of three consecutive beats. Simultaneous ECG monitoring was carried out in each patient. Left ventricular diameters, wall thickness, mass, systolic and diastolic volumes, ejection fraction (Simpson's rule biplane method), LA area and fractional area change [(systolic area minus diastolic area)/systolic area \%], as well as LA and LV longitudinal shortening, were calculated according to recommendations of both the American and European Societies of Echocardiography [22]. Cardiac chamber volumes and mass were indexed to body surface area.

Left ventricular systolic function strongly related to ejection fraction. Moreover, LV shape, LV strain analysis, mitral annulus posterior systolic excursion (MAPSE), and longitudinal function (tissue $\mathrm{S}^{\prime}$ velocity) were also evaluated.

We also investigated LV diastolic function by PW-Doppler, sampling the mitral inflow early and late diastolic velocities (E-wave and A-wave, respectively, and E/A ratio) and tissue-Doppler velocity both at basal septum level and lateral mitral annulus ( $E^{\prime}$ velocity, $A^{\prime}$ velocity and $E / E^{\prime}$ ratio).

A dedicated strain software package (X-Strain TM by Esaote, Florence, Italy) was used for both LA and LV longitudinal strain [23]. Good quality imaging with an adequate frame rate (50-70 frames per second) was needed for this purpose. Data were digitally stored and analyzed by a Fourier equation that warrants heart motion periodicity-based accuracy. Strain curves were generated by a feature-tracking mode (Figure 2). Strain measurements were generated by processing the region of interest (several endocardial points from either parasternal short axis or apical 4-chamber view). Left ventricular longitudinal and circumferential strains are negative, whereas radial strain and peak atrial longitudinal strain (PALS) are positive values.

\subsection{Statistical Analysis}

Descriptive statistical analyses were performed to evaluate basal demographic and clinical characteristics. All results were expressed as medians with interquartile range (IQ) for continuous variables, and absolute and percentage frequencies for categorical variables.

All variables were evaluated at basal time and after 12 months of treatment, and percentage changes from baseline were evaluated at the end of the treatment in both genistein and placebo patients to determine the differences between groups.

The Kolmogorov-Smirnov test for normality was performed to evaluate normal distribution. Since some of the numerical variables were not normally distributed and the low sample number did not guarantee valid asymptotic results, a non-parametric approach was used.

The U Mann-Whitney test for independent values was applied to compare characteristics of the randomized subjects, according to treatment group. In addition, differences within group for paired measurements were tested by the Wilcoxon signed-rank test analysis. 
Statistical analyses were performed using Statistical Package for Social Science (SPSS Statistics 17.0, Chicago, IL, USA) software for Windows package. $p<0.05$ was considered statistically significant.

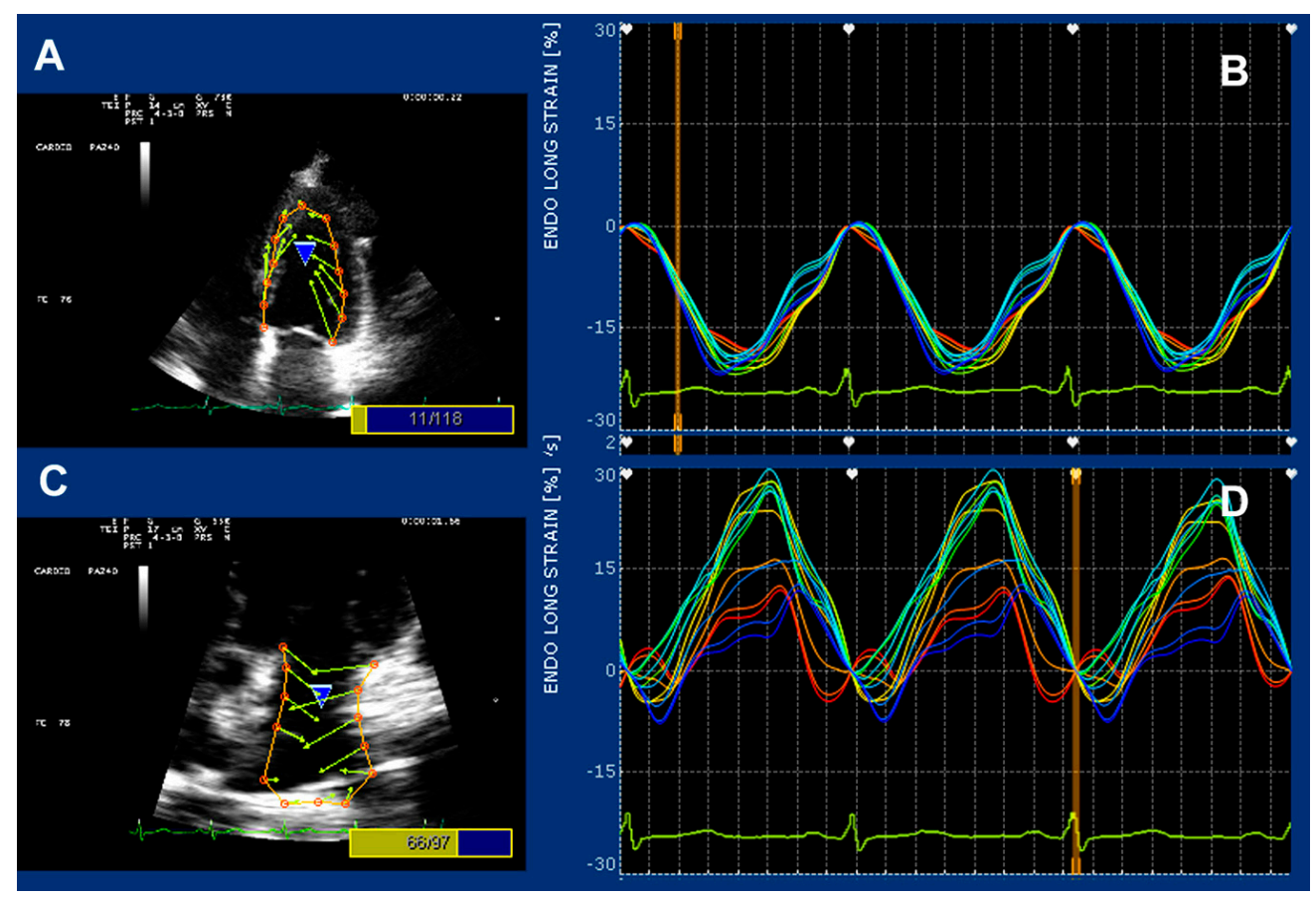

Figure 2. Strain-featured processing from the four-chamber apical view in a genistein patient. Vectors and curves are generated by processing 13 endocardial points on either the left ventricular (panels (A) and (B)) or the left atrial wall (panels (C) and (D)).

\section{Results}

\subsection{Baseline Characteristics}

A total of 22 patients, aged 55 (IQ 6) years, were enrolled from the main randomized controlled trial: 11 from the genistein and 11 from the control group, respectively. No differences in clinical, laboratory, or morphofunctional values between groups were shown at basal. Adherence to diet and exercise was similar between groups. All patients met the criteria for MetS diagnosis. Eighteen patients $(82 \%)$, nine in each group, showed mild to moderate systemic hypertension with no differences in systolic-diastolic mean pressure between groups. Waist circumference $>88 \mathrm{~cm}$ was measured in eight (73\%) genistein patients and nine (82\%) controls (ns). Five (45\%) and six (54\%) patients were obese in the genistein and placebo groups, respectively. The characteristics of patients in each group at basal and after 12 months are described in Table 1. Resting ECG was normal in all patients. None of patients were treated with glitazones. Beta blockers users were one in the genistein and two in the placebo group. Angiotensin-converting enzyme inhibitors or Angiotensin II receptor antagonist users were nine in the genistein and 10 in the placebo group.

\subsection{Clinical and Laboratory Results at Follow-Up}

All patients completed the study. Genistein levels increased from $15 \mathrm{nmol} / \mathrm{L}$ (95\%CI 7.3-22.6) at baseline to $780 \mathrm{nmol} / \mathrm{L}(95 \% \mathrm{CI} 741.7-818.3)$ at 12 months in treated subjects. BMI and waist values were similar at the end of follow-up in both groups. Resting blood pressure was on target in the majority of patients $(90 \%)$ and no differences from basal to the end of follow-up or between groups were observed. Fasting glucose and insulin levels were similar at the beginning and the end of follow-up in both groups. After 12 months of treatment, HOMA-IR $(p=0.007)$, visfatin $(p=0.016)$, 
and homocysteine $(p=0.034)$ significantly decreased in the genistein group compared to the controls. Conversely, serum adiponectin increased in the genistein, but not significantly, compared to the control group at the end of the treatment (Table 2). Changes in total cholesterol, LDL cholesterol, HDL cholesterol, and triglycerides at the end of the treatment were similar between groups.

Table 1. Clinical, laboratory, and morphofunctional values measured at baseline and after 12 months, stratified by treatment groups.

\begin{tabular}{|c|c|c|c|c|c|c|}
\hline \multirow{2}{*}{ Parameters } & \multicolumn{3}{|c|}{ Genistein } & \multicolumn{3}{|c|}{ Controls } \\
\hline & $\begin{array}{l}\text { Basal Median } \\
\text { (IQ) }\end{array}$ & $\begin{array}{c}12 \text { Month } \\
\text { Median (IQ) }\end{array}$ & $\begin{array}{c}\# p \\
\text { Value }\end{array}$ & $\begin{array}{l}\text { Basal Median } \\
\text { (IQ) }\end{array}$ & $\begin{array}{c}12 \text { Month } \\
\text { Median (IQ) }\end{array}$ & $\begin{array}{c}\# p \\
\text { Value }\end{array}$ \\
\hline Body mass index $\left(\mathrm{kg} / \mathrm{m}^{2}\right)$ & $30.3(5.0)$ & $31.5(7.0)$ & 0.167 & $30.4(11.2)$ & $29.9(10.8)$ & 0.593 \\
\hline Waist circumference $(\mathrm{cm})$ & $105.0(16.0)$ & $104.0(25.0)$ & 0.798 & $99.0(19.0)$ & $98.0(17.0)$ & 0.438 \\
\hline Systolic blood pressure (mm Hg) & $130.0(38.0)$ & $120.0(40.0)$ & 0.075 & $130.0(30.0)$ & $130.0(20.0)$ & 0.320 \\
\hline Diastolic blood pressure ( $\mathrm{mm} \mathrm{Hg}$ ) & $80.0(15.0)$ & $70.0(30.0)$ & 0.085 & $80.0(10.0)$ & $80.0(0.0)$ & 0.496 \\
\hline Fasting glucose $(\mathrm{mmol} / \mathrm{L})$ & $7.1(2.7)$ & $7.0(0.9)$ & 0.099 & $7.8(2.2)$ & $6.5(4.3)$ & 0.959 \\
\hline Total cholesterol (mmol/L) & $4.9(1.4)$ & $4.2(0.7)$ & 0.003 & $4.9(1.1)$ & $4.4(1.1)$ & 0.051 \\
\hline LDL-cholesterol (mmol/L) & $2.9(1.1)$ & $1.6(0.8)$ & 0.009 & $2.8(1.3)$ & $2.5(0.6)$ & 0.120 \\
\hline HDL-cholesterol (mmol/L) & $1.3(0.7)$ & $1.5(0.6)$ & 0.093 & $1.3(0.4)$ & $1.4(0.6)$ & 0.798 \\
\hline Triglycerides (mmol/L) & $1.5(0.9)$ & $1.2(0.8)$ & 0.008 & $1.4(0.8)$ & $1.2(0.7)$ & 0.075 \\
\hline Insulin levels (nUI/L) & $9.7(7.8)$ & $8.5(5.3)$ & 0.050 & $12.2(12.3)$ & $13.4(17.9)$ & 0.477 \\
\hline HOMA-IR & $3.4(1.5)$ & $3.0(1.7)$ & 0.010 & $3.7(4.8)$ & $4.7(5.2)$ & 0.110 \\
\hline Visfatin (ng/mL) & $3.1(2.0)$ & $1.3(0.7)$ & 0.016 & $2.1(2.2)$ & $2.4(1.3)$ & 0.477 \\
\hline Adiponectin $(\mu \mathrm{g} / \mathrm{mL})$ & $6.2(1.1)$ & $8.0(5.9)$ & 0.003 & $5.3(2.6)$ & $6.2(2.6)$ & 0.021 \\
\hline Homocysteine ( $\mu \mathrm{mol} / \mathrm{L})$ & $13.3(15.3)$ & $10.0(2.2)$ & 0.003 & $17.5(10.8)$ & $14.2(7.7)$ & 0.091 \\
\hline \multicolumn{7}{|l|}{ Left Ventricle } \\
\hline End-diastolic diameter (mm) & $47.4(9.2)$ & $46.2(8.2)$ & 0.929 & $45.8(7.7)$ & $44.2(5.1)$ & 0.859 \\
\hline BSA-index mass $\left(\mathrm{g} / \mathrm{m}^{2}\right)$ & $82.9(33.7)$ & $73.0(27.8)$ & 0.657 & $78.6(15.3)$ & $84.7(19.9)$ & 1.000 \\
\hline Height-indexed mass $\left(\mathrm{g} / \mathrm{m}^{2.7}\right)$ & $38.0(27.7)$ & $44.6(16.9)$ & 0.328 & $41.1(7.9)$ & $39.2(11.6)$ & 0.859 \\
\hline End-diastolic volume (mL) & $67.0(14.9)$ & $65.0(26.0)$ & 0.533 & $72.0(23.0)$ & $70.0(28.0)$ & 0.894 \\
\hline BSA-index end-diastolic vol. $\left(\mathrm{mL} / \mathrm{m}^{2}\right)$ & $40.3(13.9)$ & $37.9(10.5)$ & 0.328 & $37.2(10.9)$ & $39.2(15.1)$ & 0.790 \\
\hline End-diastolic shape & $0.6(0.09)$ & $0.6(0.1)$ & 0.241 & $0.6(0.08)$ & $0.6(0.1)$ & 0.859 \\
\hline Ejection fraction & $0.6(0.04)$ & $0.7(0.05)$ & 0.009 & $0.7(0.11)$ & $0.7(0.10)$ & 0.790 \\
\hline MAPSE (mm) & $15.8(4.1)$ & $16.5(1.3)$ & 0.182 & $16.3(4.8)$ & $16.0(4.9)$ & 0.790 \\
\hline TDV Septal S'-wave (cm/s) & $10.0(3.0)$ & $10.0(2.0)$ & 0.764 & $8.0(4.0)$ & $8.0(3.0)$ & 0.258 \\
\hline TDV Lateral S'-wave (cm/s) & $10.0(1.0)$ & $12.0(2.0)$ & 0.022 & $10.0(2.0)$ & $11.0(3.0)$ & 0.305 \\
\hline \multicolumn{7}{|l|}{ Left Ventricular Diastolic Indices } \\
\hline Mitral E/A velocity ratio & $1.0(0.23)$ & $0.8(0.33)$ & 0.449 & $0.8(0.44)$ & $0.9(0.28)$ & 0.965 \\
\hline Mitral E-wave DT (ms) & $204.0(16.0)$ & $216.0(13.0)$ & 0.075 & $223.0(24.0)$ & $242.0(27.0)$ & 0.059 \\
\hline $\mathrm{E} / \mathrm{E}^{\prime}$ velocity ratio & $6.8(1.0)$ & $7.5(2.6)$ & 0.533 & $7.2(3.5)$ & $7.8(3.3)$ & 0.859 \\
\hline \multicolumn{7}{|l|}{$\begin{array}{l}\text { Left Ventricular Global Strain } \\
\text { Measurements }\end{array}$} \\
\hline Radial Strain (\%) & $32.0(10.9)$ & $30.0(15.0)$ & 0.789 & $36.0(9.5)$ & $27.9(12.3)$ & 0.110 \\
\hline Circumferential Strain (\%) & $-21.0(7.7)$ & $-22.5(4.9)$ & 1.000 & $-23.5(9.2)$ & $-25.3(5.0)$ & 0.594 \\
\hline Longitudinal Strain (\%) & $-17.5(1.5)$ & $-17.3(1.6)$ & 0.328 & $-15.8(4.7)$ & $-18.8(4.9)$ & 0.213 \\
\hline \multicolumn{7}{|l|}{ Left Atrium } \\
\hline BSA-indexed ES volume $\left(\mathrm{mL} / \mathrm{m}^{2}\right)$ & $29.5(4.2)$ & $22.6(11.0)$ & 0.041 & $32.3(10.2)$ & $27.5(7.2)$ & 0.248 \\
\hline Fractional area change (\%) & $37.0(6.0)$ & $41.0(6.0)$ & 0.035 & $35.0(2.0)$ & $35.0(5.0)$ & 0.510 \\
\hline PALS (\%) & $25.5(5.8)$ & $31.0(8.5)$ & 0.021 & $23.6(10.2)$ & $24.0(6.5)$ & 0.929 \\
\hline
\end{tabular}

Values are expressed as medians with interquartile range (IQ); BSA, body surface area; DT, deceleration time; $\mathrm{E} / \mathrm{A}$, early/late diastolic velocity through the mitral inflow; E/E' velocity ratio, ratio between mitral $\mathrm{E}$ velocity and tissue E velocity; ES, end-systolic; HDL high-density lipoprotein; HOMA-IR, homeostasis model assessment for insulin resistance; LDL, low-density lipoprotein; MAPSE, mitral annular posterior systolic excursion; PALS, peak atrial longitudinal strain; $S^{\prime}$, tissue systolic velocity; TDV, tissue Doppler velocity; \# $p$-values were calculated using the Wilcoxon rank test for each group, from baseline to the end of the treatment (12 months) as well as within-group comparisons.

\subsection{Cardiac Morphofunctional Indices}

Adequate ultrasound imaging was attained from each patient. Changes in cardiac morphology and function are described in Tables 1 and 2. Both LV ejection fraction $(p=0.040)$ and LA fractional area change $(p=0.034)$ significantly increased in the genistein patients compared the to controls during the treatment. 
Additionally, LV ejection fraction $(p=0.009)$, tissue systolic wave velocity at lateral mitral annulus $(p=0.022)$, LA volume $(p=0.041)$, LA fractional area change $(p=0.035)$, and PALS $(p=0.021)$ also significantly improved in genistein-treated patients compared to basal, whereas no differences were shown in the control group. Advanced echo-strain analysis showed no relevant changes in LV radial, circumferential, and longitudinal global deformation (Table 2). No advanced LV diastolic dysfunction was observed. Grade 1-2 diastolic dysfunction was present at enrollment in two genistein patients and one control. However, at the end of follow-up, just one patient in the genistein group and four in the placebo group showed diastolic anomalies.

Table 2. Variations of clinical, laboratory values, and morphofunctional findings at Doppler echocardiography after 12 months of treatment: between groups comparison.

\begin{tabular}{|c|c|c|c|}
\hline \multirow{2}{*}{ Parameters } & \multicolumn{3}{|c|}{ Percentage Changes from Baseline after 12 Months Treatment } \\
\hline & Genistein Median (IQ) & Controls Median (IQ) & $\# p$ Value \\
\hline Body mass index $\left(\mathrm{kg} / \mathrm{m}^{2}\right)$ & $1.6(5.7)$ & $0.9(4.5)$ & 0.171 \\
\hline Waist circumference $(\mathrm{cm})$ & $0.0(4.9)$ & $0.0(4.4)$ & 0.898 \\
\hline Systolic blood pressure (mm Hg) & $0.0(11.8)$ & $0.0(12.2)$ & 0.076 \\
\hline Diastolic blood pressure ( $\mathrm{mm} \mathrm{Hg}$ ) & $-8.3(12.5)$ & $0.0(6.7)$ & 0.057 \\
\hline Fasting glucose $(\mathrm{mmol} / \mathrm{L})$ & $-7.1(23.5)$ & $-0.9(18.3)$ & 0.332 \\
\hline Total cholesterol (mmol/L) & $-12.4(14.9)$ & $-15.5(23.3)$ & 0.748 \\
\hline LDL-cholesterol (mmol/L) & $-18.1(45.1)$ & $-16.8(43.2)$ & 0.270 \\
\hline HDL-cholesterol (mmol/L) & $16.3(27.6)$ & $-2.1(15.6)$ & 0.243 \\
\hline Triglycerides (mmol/L) & $-12.5(13.8)$ & $-21.5(56.6)$ & 0.898 \\
\hline Insulin levels (nUI/L) & $-21.5(27.9)$ & $1.7(81.0)$ & 0.193 \\
\hline HOMA-IR & $-19.7(39.0)$ & $18.0(71.2)$ & 0.007 \\
\hline Visfatin (ng/mL) & $-50.9(73.2)$ & $-7.0(32.2)$ & 0.016 \\
\hline Adiponectin $(\mu \mathrm{g} / \mathrm{mL})$ & $29.4(62.8)$ & $12.6(38.6)$ & 0.088 \\
\hline Homocysteine $(\mu \mathrm{mol} / \mathrm{L})$ & $-24.3(34.4)$ & $-8.1(50.1)$ & 0.034 \\
\hline \multicolumn{4}{|l|}{ Left Ventricle } \\
\hline End-diastolic diameter (mm) & $3.2(14.7)$ & $0.2(26.5)$ & 0.949 \\
\hline BSA-index mass $\left(\mathrm{g} / \mathrm{m}^{2}\right)$ & $2.9(30.4)$ & $10.5(41.6)$ & 0.748 \\
\hline Height-indexed mass $\left(\mathrm{g} / \mathrm{m}^{2.7}\right)$ & $16.3(22.2)$ & $-5.4(45.1)$ & 0.519 \\
\hline End-diastolic volume (mL) & $-1.3(45.5)$ & $-7.8(67.8)$ & 0.898 \\
\hline BSA-index end-diastolic vol. $\left(\mathrm{mL} / \mathrm{m}^{2}\right)$ & $-0.4(49.1)$ & $7.0(48.5)$ & 1.000 \\
\hline End-diastolic shape & $3.2(5.8)$ & $-1.6(7.6)$ & 0.606 \\
\hline Ejection fraction & $20.3(12.5)$ & $-1.7(24.8)$ & 0.040 \\
\hline MAPSE (mm) & $4.4(38.0)$ & $0.6(26.4)$ & 0.606 \\
\hline TDV Septal S'-wave (cm/s) & $0.0(26.5)$ & $-12.5(48.1)$ & 0.332 \\
\hline TDV Lateral S'-wave (cm/s) & $10.0(9.1)$ & $9.1(31.3)$ & 0.606 \\
\hline \multicolumn{4}{|l|}{ Left Ventricular Diastolic Indices } \\
\hline Mitral E/A velocity ratio & $-9.8(34.8)$ & $6.0(56.8)$ & 0.652 \\
\hline Mitral E-wave DT (ms) & $10.0(12.4)$ & $6.0(11.9)$ & 0.748 \\
\hline $\mathrm{E} / \mathrm{E}^{\prime}$ velocity ratio & $6.4(72.6)$ & $3.9(49.9)$ & 0.748 \\
\hline \multicolumn{4}{|l|}{$\begin{array}{l}\text { Left Ventricular Global Strain } \\
\text { Measurements }\end{array}$} \\
\hline Radial Strain (\%) & $12.6(44.3)$ & $-13.4(35.1)$ & 0.133 \\
\hline Circumferential Strain (\%) & $0.9(30.9)$ & $3.7(38.9)$ & 0.797 \\
\hline Longitudinal Strain $(\%)$ & $-2.8(11.3)$ & $4.3(24.9)$ & 0.243 \\
\hline \multicolumn{4}{|l|}{ Left Atrium } \\
\hline BSA-indexed ES volume $\left(\mathrm{mL} / \mathrm{m}^{2}\right)$ & $-22.6(47.7)$ & $-20.8(61.1)$ & 0.151 \\
\hline Fractional area change $(\%)$ & $11.1(22.6)$ & $2.8(9.5)$ & 0.034 \\
\hline PALS (\%) & $13.3(25.4)$ & $-11.2(51.3)$ & 0.270 \\
\hline
\end{tabular}

Values are expressed as medians with interquartile range (IQ); BSA, body surface area; DT, deceleration time; $\mathrm{E} / \mathrm{A}$, early/late diastolic velocity through the mitral inflow; $\mathrm{E} / \mathrm{E}^{\prime}$ velocity ratio, ratio between mitral E velocity and tissue E velocity; ES, end-systolic; HDL high-density lipoprotein; HOMA-IR, homeostasis model assessment for insulin resistance; LDL, low-density lipoprotein; MAPSE, mitral annular posterior systolic excursion; PALS, peak atrial longitudinal strain; $S^{\prime}$, tissue systolic velocity; TDV, tissue Doppler velocity; \# $p$-values were calculated using the Wilcoxon rank test for each group, from baseline to the end of the treatment (12 months) as well as within-group comparisons.

\subsection{Adverse Events and Side-Effects}

No clinically relevant side effects, flushing, or palpitations were reported. Nobody experienced serious arrhythmias or cardiac symptoms. 


\section{Discussion}

Recent findings indicate that approximately $25 \%$ of the USA population shows traits of MetS, and the constellation of symptoms becomes of clinical concern particularly in postmenopausal patients with DM and hyperlipemia, whose CV risk is higher than that in the general population. Moreover, low adherence to treatment with lipid-lowering drugs is particularly high in female patients, strongly influenced by reimbursement criteria revision, and educational programs in primary care result in challenging efficacy in reaching the clinical targets. [8,9,24,25]. As a consequence, the increasing prevalence of MetS over the last decade hinders the efforts of physicians to improve the CV risk profile through better glycaemic homeostasis $[1,2,6,26]$.

Our group has previously recognized an improvement in the HOMA-IR and several markers of $\mathrm{CV}$ risk of MetS postmenopausal patients treated with genistein [14-16]. Furthermore, the present findings suggest an interesting impact of genistein treatment on cardiac function in this clinical setting [12].

Using the strain deformation analysis, the most advanced technique to discover early and subclinical LV impairment at the present time [23], our results suggest that one year of treatment with genistein at the dose of $54 \mathrm{mg}$ /day did not worsen LV chamber size or function. On the contrary, genistein treatment improved LV ejection fraction. Such a gain in LV systolic function cannot be exclusively attributed to a direct genistein effect on myocardium, but could rather depend on several factors, including the improvement in adipokine serum levels. In addition, the lack of improvement in the control group emphasizes the efficacy of the treatment with genistein. Similarly, the improvement in the LA size and function has been limited to the genistein group. These patients showed a decrease in LA systolic volume index together with a raise in fractional area change and PALS, without changes in systo-diastolic blood pressure. This finding is particularly interesting since patients with DM and hypertension, or MetS, have an increased risk of atrial fibrillation and heart failure [27-29].

Therefore, the present study suggests that genistein could also reduce the LA afterload and potential dysfunction. In fact, hypertensive, diabetic, and overweight patients have an increased risk of atrial dysfunction. Significant changes in LA volume and longitudinal deformation might contribute to the reduction of LA dilatation, fibrosis, and the occurrence of atrial fibrillation, regardless of the loading conditions at the time of examination $[27,28]$.

The cardioprotective effects of genistein could be partially justified by the improvement in the adipokine profile. Adiponectin increased significantly over the 12 months in both groups and the change was not significantly different between groups. Adiponectin promotes insulin-sensitizing effects and peripheral glucose use, as previously reported [16]. Low circulating levels of adiponectin were found in obese patients with type-2 DM, as well as in postmenopausal MetS women [30-33]. Adiponectin is a modulator of vascular remodeling, and low serum adiponectin levels are predictors of atherosclerosis and myocardial infarction, and are associated with higher incidence of cardiovascular events [34]. These effects are probably related to the anti-inflammatory action of adiponectin, in fact, it reduces the production of inflammatory cytokines and adhesion molecules in endothelial cells [35].

On the contrary, the pro-inflammatory visfatin was reduced by genistein after one year of treatment. Visfatin increase in type-2 DM patients was related to heart failure and acute coronary syndromes [36-39]; visfatin appears to mediate vascular endothelial inflammation by inducing the expression of adhesion molecules (VCAM-1 and ICAM-1) and pro-inflammatory cytokines such as IL-1 $\beta$, IL-6, and TNF- $\alpha$ [40]. These effects on adipokines might explain the observed protective effect on myocardium. Genistein, by reducing HOMA-IR, may also decrease glucose-mediated cardiotoxicity, lowering glycated proteins and reactive oxygen species, which are involved in the pathogenesis of interstitial fibrosis in diabetic cardiomyopathy [41,42].

Among the pro-inflammatory factors, homocysteine, which has been suggested as an independent risk factor for endothelial dysfunction and atherosclerosis [43], was also reduced by genistein. Since homocysteine could indirectly impact cardiac function in women with MetS, its reduction in 
genistein-treated patients confirms our previous data obtained in healthy postmenopausal subjects [16] regarding the possible cardioprotective role of this isoflavone.

Despite the intriguing present results, some limitations of the study should be taken into account. Our results were obtained from a population without signs of cardiac dysfunction and all women were of Caucasian origin, thus we do not know if the same effects could be reproduced in different ethnic groups. The small sample size is a limitation of the present study and no definitive conclusions can be drawn from our proof of concept study. However, this study was able to demonstrate, for the first time, that genistein significantly improved cardiovascular function in postmenopausal women with metabolic syndrome. Accordingly, using this preliminary information, a future larger study expressly designed to evaluate the effect of genistein on cardiac function is encouraged.

In conclusion, our preliminary data suggest that a daily supplementation with $54 \mathrm{mg}$ of pure genistein improves both LA remodeling and LV function in postmenopausal women with MetS.

Acknowledgments: This study was funded by Italian Ministry of University and Research (grant number 20073XZSR3).

Author Contributions: V.A., C.D.G., H.M., G.L., F.S. conceived and designed the experiments; C.D.G., H.M., A.D.B., C.I., G.D.V., S.C. performed the experiments; V.A., A.A., S.C. analyzed the data; M.A., R.G., E.A., D.P., A.B., D.A. contributed reagents/materials/analysis tools; V.A., C.D.G., F.S., A.B. wrote the paper. All authors approved the final version of the manuscript.

Conflicts of Interest: The authors declare no conflict of interest.

\section{References}

1. Giampaoli, S.; Stamler, J.; Donfrancesco, C.; Panico, S.; Vanuzzo, D.; Cesana, G.; Mancia, G.; Pilotto, L.; Mattiello, A.; Chiodini, P.; et al. The metabolic syndrome: A critical appraisal based on the cuore epidemiologic study. Prev. Med. 2009, 48, 525-531. [CrossRef] [PubMed]

2. Janssen, I.; Powell, L.H.; Crawford, S.; Lasley, B.; Sutton-Tyrrell, K. Menopause and the metabolic syndrome: The study of women's health across the nation. Arch. Intern. Med. 2008, 168, 1568-1575. [CrossRef] [PubMed]

3. Xing, D.; Nozell, S.; Chen, Y.F.; Hage, F.; Oparil, S. Estrogen and mechanisms of vascular protection. Arterioscler. Thromb. Vasc. Biol. 2009, 29, 289-295. [CrossRef] [PubMed]

4. Yang, X.P.; Reckelhoff, J.F. Estrogen, hormonal replacement therapy and cardiovascular disease. Curr. Opin. Nephrol. Hypertens. 2011, 20, 133-138. [CrossRef] [PubMed]

5. Caputi, A.P.; Arcoraci, V.; Benvenuti, C. Soy isoflavones, lactobacilli, vitamin d3 and calcium. Observational study in menopause. G. Ital. Ostet. Ginecol. 2006, 28, 212-221.

6. Bonora, E.; Targher, G.; Formentini, G.; Calcaterra, F.; Lombardi, S.; Marini, F.; Zenari, L.; Saggiani, F.; Poli, M.; Perbellini, S.; et al. The metabolic syndrome is an independent predictor of cardiovascular disease in type 2 diabetic subjects. Prospective data from the verona diabetes complications study. Diabet. Med. J. Br. Diabet. Assoc. 2004, 21, 52-58. [CrossRef]

7. Rexrode, K.M.; Manson, J.E.; Lee, I.M.; Ridker, P.M.; Sluss, P.M.; Cook, N.R.; Buring, J.E. Sex hormone levels and risk of cardiovascular events in postmenopausal women. Circulation 2003, 108, 1688-1693. [CrossRef] [PubMed]

8. Ferrajolo, C.; Arcoraci, V.; Sullo, M.G.; Rafaniello, C.; Sportiello, L.; Ferrara, R.; Cannata, A.; Pagliaro, C.; Tari, M.G.; Caputi, A.P.; et al. Pattern of statin use in southern italian primary care: Can prescription databases be used for monitoring long-term adherence to the treatment? PLoS ONE 2014, 9, e102146. [CrossRef] [PubMed]

9. Trifiro, G.; Alacqua, M.; Corrao, S.; Moretti, S.; Tari, D.U.; Galdo, M.; Caputi, A.P.; Arcoraci, V. Lipid-lowering drug use in italian primary care: Effects of reimbursement criteria revision. Eur. J. Clin. Pharmacol. 2008, 64, 619-625. [CrossRef] [PubMed]

10. Trifiro, G.; Alacqua, M.; Corrao, S.; Tari, M.; Arcoraci, V. Statins for the primary prevention of cardiovascular events in elderly patients: A picture from clinical practice without strong evidence from clinical trials. J. Am. Geriatr. Soc. 2008, 56, 175-177. [CrossRef] [PubMed]

11. Nilsson, S.; Gustafsson, J.A. Estrogen receptors: Therapies targeted to receptor subtypes. Clin. Pharmacol. Ther. 2011, 89, 44-55. [CrossRef] [PubMed] 
12. Sbarouni, E.; Iliodromitis, E.K.; Zoga, A.; Vlachou, G.; Andreadou, I.; Kremastinos, D.T. The effect of the phytoestrogen genistein on myocardial protection, preconditioning and oxidative stress. Cardiovasc. Drugs Ther. Spons. Int. Soc. Cardiovasc. Pharmacother. 2006, 20, 253-258. [CrossRef] [PubMed]

13. Taylor, H.S.; Manson, J.E. Update in hormone therapy use in menopause. J. Clin. Endocrinol. Metab. 2011, 96, 255-264. [CrossRef] [PubMed]

14. Irace, C.; Marini, H.; Bitto, A.; Altavilla, D.; Polito, F.; Adamo, E.B.; Arcoraci, V.; Minutoli, L.; Di Benedetto, A.; Di Vieste, G.; et al. Genistein and endothelial function in postmenopausal women with metabolic syndrome. Eur. J. Clin. Investig. 2013, 43, 1025-1031. [CrossRef] [PubMed]

15. Marini, H.; Bitto, A.; Altavilla, D.; Burnett, B.P.; Polito, F.; Di Stefano, V.; Minutoli, L.; Atteritano, M.; Levy, R.M.; Frisina, N.; et al. Efficacy of genistein aglycone on some cardiovascular risk factors and homocysteine levels: A follow-up study. Nutr. Metab. Cardiovasc. Dis. NMCD 2010, 20, 332-340. [CrossRef] [PubMed]

16. Squadrito, F.; Marini, H.; Bitto, A.; Altavilla, D.; Polito, F.; Adamo, E.B.; D'Anna, R.; Arcoraci, V.; Burnett, B.P.; Minutoli, L.; et al. Genistein in the metabolic syndrome: Results of a randomized clinical trial. J. Clin. Endocrinol. Metab. 2013, 98, 3366-3374. [CrossRef] [PubMed]

17. Arcoraci, V.; Atteritano, M.; Squadrito, F.; D'Anna, R.; Marini, H.; Santoro, D.; Minutoli, L.; Messina, S.; Altavilla, D.; Bitto, A. Antiosteoporotic activity of genistein aglycone in postmenopausal women: Evidence from a post-hoc analysis of a multicenter randomized controlled trial. Nutrients 2017, 9. [CrossRef] [PubMed]

18. Bitto, A.; Granese, R.; Triolo, O.; Villari, D.; Maisano, D.; Giordano, D.; Altavilla, D.; Marini, H.; Adamo, E.B.; Nicotina, P.A.; et al. Genistein aglycone: A new therapeutic approach to reduce endometrial hyperplasia. Phytomedicine 2010, 17, 844-850. [CrossRef] [PubMed]

19. Grundy, S.M.; Cleeman, J.I.; Daniels, S.R.; Donato, K.A.; Eckel, R.H.; Franklin, B.A.; Gordon, D.J.; Krauss, R.M.; Savage, P.J.; Smith, S.C., Jr.; et al. Diagnosis and management of the metabolic syndrome: An american heart association/national heart, lung, and blood institute scientific statement. Circulation 2005, 112, 2735-2752. [CrossRef] [PubMed]

20. Task Force, M.; Ryden, L.; Grant, P.J.; Anker, S.D.; Berne, C.; Cosentino, F.; Danchin, N.; Deaton, C.; Escaned, J.; Hammes, H.P.; et al. Esc guidelines on diabetes, pre-diabetes, and cardiovascular diseases developed in collaboration with the easd: The task force on diabetes, pre-diabetes, and cardiovascular diseases of the european society of cardiology (esc) and developed in collaboration with the european association for the study of diabetes (easd). Eur. Heart J. 2013, 34, 3035-3087.

21. Bitto, A.; Burnett, B.P.; Polito, F.; Russo, S.; D’Anna, R.; Pillai, L.; Squadrito, F.; Altavilla, D.; Levy, R.M. The steady-state serum concentration of genistein aglycone is affected by formulation: A bioequivalence study of bone products. Biomed. Res. Int. 2013, 2013, 273498. [CrossRef] [PubMed]

22. Lang, R.M.; Bierig, M.; Devereux, R.B.; Flachskampf, F.A.; Foster, E.; Pellikka, P.A.; Picard, M.H.; Roman, M.J.; Seward, J.; Shanewise, J.; et al. Recommendations for chamber quantification. Eur. J. Echocardiogr. J. Work. Group Echocardiogr. Eur. Soc. Cardiol. 2006, 7, 79-108. [CrossRef] [PubMed]

23. Mor-Avi, V.; Lang, R.M.; Badano, L.P.; Belohlavek, M.; Cardim, N.M.; Derumeaux, G.; Galderisi, M.; Marwick, T.; Nagueh, S.F.; Sengupta, P.P.; et al. Current and evolving echocardiographic techniques for the quantitative evaluation of cardiac mechanics: Ase/eae consensus statement on methodology and indications endorsed by the japanese society of echocardiography. Eur. J. Echocardiogr. J. Work. Group Echocardiogr. Eur. Soc. Cardiol. 2011, 12, 167-205. [CrossRef] [PubMed]

24. Arcoraci, V.; Santoni, L.; Ferrara, R.; Furneri, G.; Cannata, A.; Sultana, J.; Moretti, S.; Di Luccio, A.; Tari, D.U.; Pagliaro, C.; et al. Effect of an educational program in primary care: The case of lipid control in cardio-cerebrovascular prevention. Int. J. Immunopathol. Pharmacol. 2014, 27, 351-363. [CrossRef] [PubMed]

25. Corrao, S.; Arcoraci, V.; Arnone, S.; Calvo, L.; Scaglione, R.; Di Bernardo, C.; Lagalla, R.; Caputi, A.P.; Licata, G. Evidence-based knowledge management: An approach to effectively promote good health-care decision-making in the information era. Intern. Emerg. Med. 2009, 4, 99-106. [CrossRef] [PubMed]

26. McCullough, A.J. Epidemiology of the metabolic syndrome in the USA. J. Dig. Dis. 2011, 12, 333-340. [CrossRef] [PubMed]

27. Li, S.H.; Yang, B.; Gong, H.P.; Tan, H.W.; Zhong, M.; Zhang, Y.; Zhang, W. Impaired atrial synchronicity in patients with metabolic syndrome associated with insulin resistance and independent of hypertension. Hypertens. Res. Off. J. Jpn. Soc. Hypertens. 2009, 32, 791-796. [CrossRef] [PubMed] 
28. Lin, K.J.; Cho, S.I.; Tiwari, N.; Bergman, M.; Kizer, J.R.; Palma, E.C.; Taub, C.C. Impact of metabolic syndrome on the risk of atrial fibrillation recurrence after catheter ablation: Systematic review and meta-analysis. J. Interv. Card. Electrophysiol. Int. J. Arrhythm. Pacing 2014, 39, 211-223. [CrossRef] [PubMed]

29. Seo, J.M.; Park, T.H.; Lee, D.Y.; Cho, Y.R.; Baek, H.K.; Park, J.S.; Kim, M.H.; Kim, Y.D.; Choi, S.Y.; Lee, S.M.; et al. Subclinical myocardial dysfunction in metabolic syndrome patients without hypertension. J. Cardiovasc. Ultrasound 2011, 19, 134-139. [CrossRef] [PubMed]

30. Gil-Campos, M.; Canete, R.R.; Gil, A. Adiponectin, the missing link in insulin resistance and obesity. Clin. Nutr. 2004, 23, 963-974. [CrossRef] [PubMed]

31. Havel, P.J. Control of energy homeostasis and insulin action by adipocyte hormones: Leptin, acylation stimulating protein, and adiponectin. Curr. Opin. Lipidol. 2002, 13, 51-59. [CrossRef] [PubMed]

32. Northcott, J.M.; Yeganeh, A.; Taylor, C.G.; Zahradka, P.; Wigle, J.T. Adipokines and the cardiovascular system: Mechanisms mediating health and disease. Can. J. Physiol. Pharmacol. 2012, 90, 1029-1059. [CrossRef] [PubMed]

33. Rabe, K.; Lehrke, M.; Parhofer, K.G.; Broedl, U.C. Adipokines and insulin resistance. Mol. Med. 2008, 14, 741-751. [CrossRef] [PubMed]

34. Diaz-Melean, C.M.; Somers, V.K.; Rodriguez-Escudero, J.P.; Singh, P.; Sochor, O.; Llano, E.M.; Lopez-Jimenez, F. Mechanisms of adverse cardiometabolic consequences of obesity. Curr. Atheroscler. Rep. 2013, 15, 364. [CrossRef] [PubMed]

35. Ouchi, N.; Walsh, K. Cardiovascular and metabolic regulation by the adiponectin/c1q/tumor necrosis factor-related protein family of proteins. Circulation 2012, 125, 3066-3068. [CrossRef] [PubMed]

36. Bitto, A.; Arcoraci, V.; Alibrandi, A.; D’Anna, R.; Corrado, F.; Atteritano, M.; Minutoli, L.; Altavilla, D.; Squadrito, F. Visfatin correlates with hot flashes in postmenopausal women with metabolic syndrome: Effects of genistein. Endocrine 2017, 55, 899-906. [CrossRef] [PubMed]

37. Grzywocz, P.; Mizia-Stec, K.; Wybraniec, M.; Chudek, J. Adipokines and endothelial dysfunction in acute myocardial infarction and the risk of recurrent cardiovascular events. J. Cardiovasc. Med. 2015, 16, 37-44.

38. Romacho, T.; Sanchez-Ferrer, C.F.; Peiro, C. Visfatin/nampt: An adipokine with cardiovascular impact. Med. Inflamm. 2013, 2013, 946427. [CrossRef] [PubMed]

39. Straburzynska-Migaj, E.; Pilaczynska-Szczesniak, L.; Nowak, A.; Straburzynska-Lupa, A.; Sliwicka, E.; Grajek, S. Serum concentration of visfatin is decreased in patients with chronic heart failure. Acta Biochim. Pol. 2012, 59, 339-343. [PubMed]

40. Mattu, H.S.; Randeva, H.S. Role of adipokines in cardiovascular disease. J. Endocrinol. 2013, 216, T17-T36. [CrossRef] [PubMed]

41. Bugyei-Twum, A.; Advani, A.; Advani, S.L.; Zhang, Y.; Thai, K.; Kelly, D.J.; Connelly, K.A. High glucose induces smad activation via the transcriptional coregulator p300 and contributes to cardiac fibrosis and hypertrophy. Cardiovasc. Diabetol. 2014, 13, 89. [CrossRef] [PubMed]

42. Hintz, K.K.; Ren, J. Phytoestrogenic isoflavones daidzein and genistein reduce glucose-toxicity-induced cardiac contractile dysfunction in ventricular myocytes. Endocr. Res. 2004, 30, 215-223. [CrossRef] [PubMed]

43. Abraham, J.M.; Cho, L. The homocysteine hypothesis: Still relevant to the prevention and treatment of cardiovascular disease? Clevel. Clin. J. Med. 2010, 77, 911-918. [CrossRef] [PubMed]

(C) 2017 by the authors. Licensee MDPI, Basel, Switzerland. This article is an open access article distributed under the terms and conditions of the Creative Commons Attribution (CC BY) license (http://creativecommons.org/licenses/by/4.0/). 